\title{
ĐẶC ĐIỂM RỐI LOẠN GIẤC NGỦ TRÊN BỆNH NHÂN ĐÁI THÁO ĐƯờNG CAO TUỔI TẠI BÊNH VIỆN Y HỌC CỔ TRUYỀN HÀ ĐÔNG Nguyễn Thị Thu Huơng ${ }^{1,2}$, Nguyễ̂n Thị Thùy Duong ${ }^{3}$, Nguyễ̂n Trung Anh ${ }^{1,2}$
}

1. Bệnh viện Lão khoa Trung ưong

2. Trường Đại hoc Y Hà Nội

DOI: $10.47122 / v j d e .2020 .43 .1$

\section{Bệnh viện Y học cổ truyền Hà Đông}

\section{ABSTRACT \\ Characteristics of sleep disturbance in elderly diabetic patients at Ha Dong Traditional Medicine Hospital}

Objectives: To assess the rate of poor sleep quality and sleep disorder characteristics in elderly diabetic patients at $\mathrm{Ha}$ Dong Traditional Medicine Hospital. Methods: A cross-sectional study was performed in 107 patients aged 60 years or older, who was examined and treated at the $\mathrm{Ha}$ Dong Traditional Medicine Hospital. The subjects were interviewed by the a unified medical record, sleep disturbances was diagnosed according to PSQI questionnaire. Results: The average age was $66.1 \pm 6.4$ years, the female/male ratio was 1.97 . The rate of poor sleep quality was $89.7 \%$. On the 7 dimensions of sleep disturbance evaluation, the majority of patients had relatively poor levels of quality of sleep. There was no statistically significant relationship between age, gender, living area, number of comorbidities, duration of diabetes, hypoglycemia and complications of diabetes with poor sleep quality. Conclusion: The incidence of poor sleep quality in elderly diabetic patients who were examined and treated at Ha Dong Traditional Medicine Hospital was high, therefore, it isnecessary for screening and early diagnosis of sleep disorders in this population.

Key words: Sleep disorder, diabetes, older person

\section{TÓM TẮT}

Mục tiêu: Đánh giá tỷ lệ chất lượng giấc ngủ kém và đặc điểm rối loạn giấc ngủ trên bệnh nhân ĐTĐ cao tuổi tại bệnh viện y học cổ truyền Hà Đông. Đối tương và phuơng pháp: Nghiên cứu mô tả cắt ngang trên 107 bệnh nhân $\geq 60$ tuổi đến khám và điều trị tại bệnh viện $\mathrm{Y}$ học cổ truyền Hà Đông. Đối tượng nghiên cứu được phỏng vấn theo mẫu bệnh án thống nhất, chẩn đoán chất lượng giấc ngủ kém dựa trên thang điểm PSQI. Kết quả: Tuổi trung bình là $66,1 \pm 6,4$ tuổi, tỷ lệ nữ/nam là 1,97 .Tỷ lệ chất lượng giấc ngủ kém là $89,7 \%$. Trên 7 phương diện đánh giá rối loạn giấc ngủ, đa số các bệnh nhân có mức độ chất lượng/rối loạn giấc ngủ ở mức tương đối kém. Không có mối liên quan có ý nghĩa thống kê giữa tuổi, giới, nơi sống, số bệnh đồng mắc, thời gian mắc đái tháo đường, hạ đường huyết và số biến chứng của ĐTĐ với tỉ lệ chất lượng giấc ngủ kém ở đối tượng nghiên cứu. Kết luận: Tỷ lệ chất lượng giấc ngủ kém trên bệnh nhân ĐTĐ cao tuổi khám và điều trị tại bệnh viện $\mathrm{Y}$ học cổ truyền Hà Đông cao, do vậy cần sàng lọc và chẩn đoán sớm tình trạng rối loạn giấc ngủ trên người cao tuổi mắc ĐTĐ.

Tù khóa: Rối loạn giấc ngủ, đái tháo đường, cao tuổi.

Chịu trách nhiệm chính: Nguyễn Thị Thu Hương

Ngày nhận bài: 02/11/2020

Ngày phản biện khoa học: 08/11/2020

Ngày duyệt bài: 11/12/2020

Email: thuhuonglk@hmu.edu.vn

Điện thoại: 0973056334

\section{1. ĐĂT VẤN ĐỀ}

Đái tháo đường (ĐTĐ) đang ngày càng gia tăng trên toàn thế giới và là một gánh nặng lớn cho toàn xã hội. Theo Liên đoàn ĐTĐ thế giới (International Diabetes Federation - IDF) năm 2015 số người mắc ĐTĐ là 415 triệu người, dự kiến sẽ tăng lên 642 triệu vào năm 2040 [1]. Theo Tổ chức Y tế thế giới (World 
Health Organization - WHO) đến 2030 sẽ có hơn nửa số mắc ĐTĐ trên thế giới là dân châu Á và hơn phân nửa số bệnh nhân này trên tuổi $60(53 \%)$ [2]. ĐTĐ và các vấn đề sức khỏe liên quan gây ra gánh nặng đáng kể về khuyết tật và suy giảm chất lượng cuộc sống đặc biệt ở người cao tuổi [3].Rối loạn giấc ngủ là một tình trạng thường gặp ở bệnh nhân ĐTĐ đặc biệt ở người cao tuồi. Tình trạng khó bắt đầu và duy trì giấc ngủ, buồn ngủ ban ngày và chất lượng giấc ngủ kém đã được báo cáo bởi những người mắc ĐTĐ. Rối loạn giấc ngủ gây nhiều hậu quả tai hại đến sức khỏe, tâm lý, khả năng làm việc của bệnh nhân... làm giảm chất lượng cuộc sống, làm ảnh hưởng không nhỏ đến hiệu quả điều trị bệnh chính.

Bệnh viện $\mathrm{Y}$ học cổ truyền Hà Đông là bênh viện chuyên khoa tuyến tỉnh với quy mô 150 giường bệnh và phòng khám đa khoa. Trong năm 2018-2019 số lượt bệnh nhân ĐTĐ khám và điều trị ngoại trú ngày càng tăng. Tuy nhiên, rối loạn giấc ngủ ở bệnh nhân cao tuổi có ĐTĐ chưa được quan tâm nhiều. Tìm hiểu về vấn đề này giúp nâng cao hiệu quả điều trị và chất lượng cuộc sống cho bệnh nhân. Do đó, chúng tôi tiến hành nghiên cứu đề tài này với mục tiêu xác định tỷ lệ chất lượng giấc ngủ kém và đặc điểm rối loạn giấc ngủ trên bệnh nhân ĐTĐ cao tuổi tại bệnh viện y học cổ truyền Hà Đông.

\section{2. ĐỐI TƯợNG VÀ PHƯƠNG PHÁP NGHIÊN CÚU}

Nghiên cứu được thực hiện trên 107 bệnh nhân ĐTĐ cao tuổi khám và điều trị tại bệnh viện $\mathrm{Y}$ học cổ truyền Hà Đông từ tháng 05/2019 đến tháng $11 / 2019$.

\section{1. Đối tượng nghiên cứu}

\section{KẾT QUẢ NGHIÊN CÚU}

\section{1. Đặc điểm chung}

Qua nghiên cứu trên 107 bệnh nhân ĐTĐ cao tuổi khám và điều trị tại Bệnh viện Y học cổ truyền Hà Đông từ tháng 05 đến tháng 11 năm 2019, chúng tôi đã thu được kết quả sau:

Bảng 1: Đặc điểm chung của nhóm nghiên cứu $(\mathrm{n}=107)$

\begin{tabular}{|c|c|c|}
\hline Đặc điểm & Số lượng (n) & Tỉ lệ (\%) \\
\hline Tuổi (Trung bình \pm Độ lệch chuẩn) & \multicolumn{2}{|c|}{$66,1 \pm 6,4$} \\
\hline
\end{tabular}

Tiêu chuẩn chọn đối tượngnghiêncứu:Bệnh nhân $\mathrm{ĐTÐ} \geq 60$ tuổi khám và điều trị tại Bệnh viện $\mathrm{Y}$ học cổ truyền Hà Đông.

Tiêu chuẩn loại trừ: Bệnh nhân mắc bệnh cấp tính nặng không thể tham gia hoặc không thể hoàn thành bộ câu hỏi phỏng vấn; bệnh nhân không đồng ý tham gia nghiên cứu.

\subsection{Phương pháp nghiên cứu}

Phương pháp mô tả cắt ngang, chọn mẫu toàn bộ. Quá trình thăm khám được tiến hành theo mẫu bệnh án thống nhất. Các biến số nghiên cứu: Chẩn đoán rối loạn giấc ngủ theo chỉ số chất lượng giấc ngủ Pittsburgh (Pittsburgh Sleep Quality Index - PSQI) [4]. PSQI được chia thành 7 lĩnh vực đánh giá: chất lượng giấc ngủ chủ quan, độ trễ giấc ngủ, thời gian ngủ, hiệu quả giấc ngủ và rối loạn giấc ngủ, sử dụng thuốc ngủ và rối loạn chức năng ban ngày. Kết quả dựa trên điểm số từ 0 đến 3 : điểm 0 tương ứng không rối loạn giấc ngủ/ngủ rất tốt/không có khó khăn gì, điểm 3 tương ứng chất lượng giấc ngủ rất kém/ngủ rất khó khăn. Đánh giá tổng điểm PSQI: $\geq 8$ điểm là chất lượng giấc ngủ kém, $<8$ điểm là giấc ngủ bình thường. Các thông tin chung về đối tượng: tuổi, giới, trình độ học vấn, nơi sống, bệnh đồng mắc, tiền sử ĐTĐ, thời gian phát hiện bệnh, tiền sử sử dụng thuốc điều trị ĐTĐ và rối loạn giấc ngủ, biến chứng của ĐТÐ

\subsection{Xử lý số liệu:}

Số liệu được xử lý và phân tích bằng phần mềm thống kê y học SPSS 16.0. Sử dụng các thuật toán: tính tỷ lệ phần trăm, tính giá trị trung bình. Sử dụng test $\chi^{2}$ để phân tích mối liên quan giữa các biến. Sự khác biệt có ý nghĩa thống kê khi $\mathrm{p}<0,05$. 


\begin{tabular}{|l|l|c|c|}
\hline \multirow{2}{*}{$\begin{array}{l}\text { Nhóm } \\
\text { tuối }\end{array}$} & $<70$ & 87 & 81,3 \\
\cline { 2 - 4 } & $\geq 70$ & 20 & 18,7 \\
\hline \multirow{2}{*}{ Giới } & Nam & 36 & 33,6 \\
\cline { 2 - 4 } & Nữ & 71 & 66,4 \\
\hline \multirow{2}{*}{$\begin{array}{l}\text { Khu vức } \\
\text { sinh sống }\end{array}$} & Nông thôn & 64 & 59,8 \\
\cline { 2 - 4 } & Thành thị & 43 & 40,2 \\
\hline \multirow{2}{*}{$\begin{array}{l}\text { Trình độ } \\
\text { học vấn }\end{array}$} & Chưa tốt nghiệp THPT & 66 & 61,7 \\
\cline { 2 - 4 } & Tốt nghiệp THPT & 33 & 30,8 \\
\cline { 2 - 4 } & Sau THPT & 8 & 7,5 \\
\hline \multirow{2}{*}{$\begin{array}{l}\text { Số bệnh đồng mắc } \\
\text { (Trung bình } \pm \text { Độ lệch chuẩn) }\end{array}$} & \multicolumn{2}{|c|}{$2,72 \pm 0,76$} \\
\hline
\end{tabular}

Trong tống số 107 đối tượng nghiên cứu có 71 bệnh nhân nữ chiếm 66,4\%, cao hơn so với 36 bệnh nhân nam chiếm 33,6\%.Tuổi trung bình của các bệnh nhân là $66,1 \pm 6,4$. Nhóm < 70 tuổi chiếm tỷ lệ cao $81,3 \%$.Nhóm bệnh nhân chưa tốt nghiệp PTTH chiếm tỷ lệ cao nhất $61,7 \%$, nhóm học trên đại học chiếm tỷ lệ thấp nhất $8,3 \% .59,8 \%$ bệnh nhân sống ở khu vực nông thôn. Số bệnh đồng mắc trung bình là $2,72 \pm 0,76$.

Bảng 2: Đặc điểm về bệnh ĐTĐ (n=107)

\begin{tabular}{|c|c|c|c|}
\hline \multicolumn{2}{|c|}{ Đặc điểm } & Số lượng (n) & Tỉ lệ (\%) \\
\hline \multicolumn{2}{|c|}{ Thời gian mắc (năm) (Trung bình \pm Độ lệch chuẩn) } & \multicolumn{2}{|c|}{$9,63 \pm 4,99$} \\
\hline \multirow{3}{*}{ Điều trị ĐTĐ } & Thuốc viên & 102 & 95,3 \\
\hline & Insulin & 5 & 4,7 \\
\hline & Thuốc viên và insulin & 3 & 2,8 \\
\hline \multicolumn{2}{|c|}{ Có hạ đường huyết trong 6 tháng qua } & 22 & 20,6 \\
\hline \multicolumn{2}{|c|}{ Số biến chứng (Trung bình \pm Độ lệch chuẩn) } & \multicolumn{2}{|c|}{$1,33 \pm 0,74$} \\
\hline
\end{tabular}

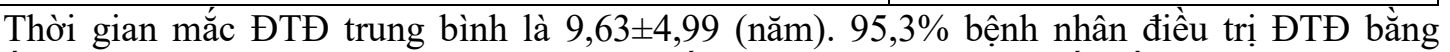
thuốc viên. $20,6 \%$ bệnh nhân có hạ đường huyết trong 6 tháng qua và số biến chứng trung bình là $1,33 \pm 0,74$.

\section{tuổi}

3.2. Tỷ lệ chất lượng giấc ngủ kém và đặc điểm rối loạn giấc ngủ ở bệnh nhân ĐTĐ cao

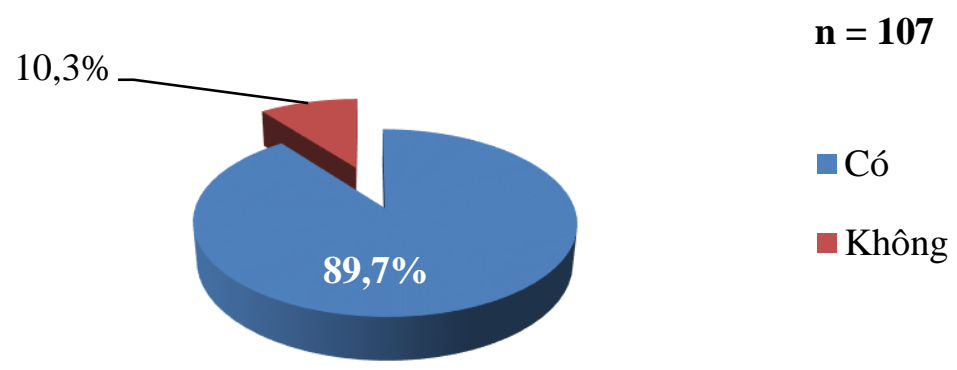

Biểu đồ 1. Tỉ lệ chất lượng giấc ngủ kém 
Trong số 107 bệnh nhân nghiên cứu thì có $89,7 \%$ bệnh nhân có chất lượng giấc ngủ kém theo thang điểm PSQI.

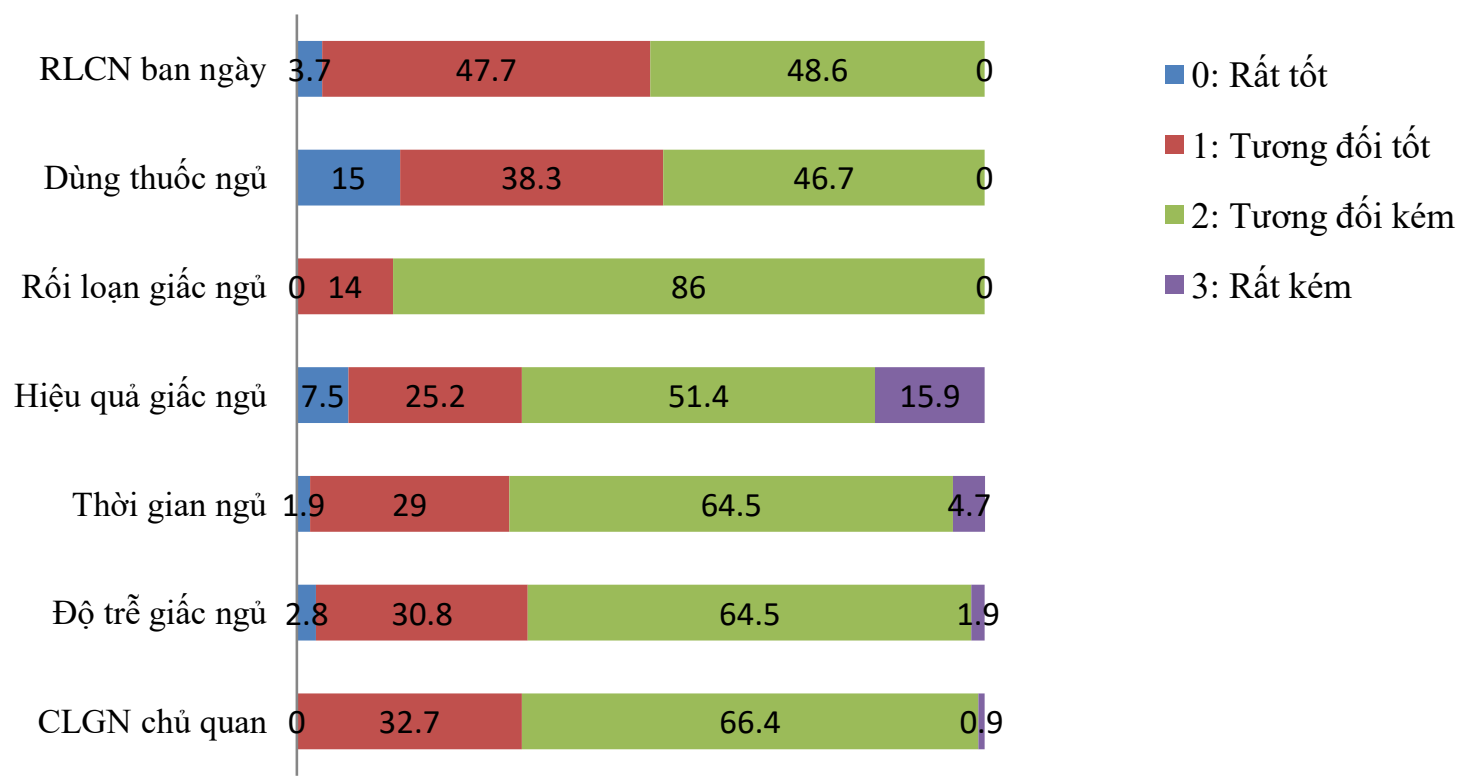

Biểu đồ 2. Đặc điểm của 7 phương diện đánh giá rối loạn giấc ngủ

Trên 7 phương diện đánh giá rối loạn giấc ngủ, đa số các bệnh nhân có mức độ chất lượng/rối loạn giấc ngủ ở mức tương đối kém.

\subsection{Một số yếu tố liên quan với chất lượng giấc ngủ kém}

Bảng 3. Mối liên quan giữa chất lượng giấc ngủ và các đặc điểm chung

\begin{tabular}{|c|c|c|c|c|}
\hline \multicolumn{2}{|c|}{ Đặc điểm } & $\begin{array}{c}\text { Chất lượng giấc ngủ } \\
\text { tốt }(\mathrm{n}=11)\end{array}$ & $\begin{array}{c}\text { Chất lượng giấc ngủ } \\
\text { kém }(\mathrm{n}=96)\end{array}$ & $\mathbf{p}$ \\
\hline \multicolumn{2}{|c|}{ Tuổi trung bình } & $66,40 \pm 6,55$ & $63,45 \pm 3,78$ & 0,147 \\
\hline \multirow{2}{*}{ Nhóm tuổi } & $<70$ & $11(12,6 \%)$ & $76(87,4 \%)$ & \multirow{2}{*}{0,121} \\
\hline & $\geq 70$ & $0(0,0 \%)$ & $20(100,0 \%)$ & \\
\hline \multirow{2}{*}{ Giới } & Nam & $6(16,7 \%)$ & $30(83,3 \%)$ & \multirow{2}{*}{0,176} \\
\hline & Nữ & $5(7,0 \%)$ & $66(93,0 \%)$ & \\
\hline \multirow{2}{*}{ Nơi sống } & Nông thôn & $7(63,6 \%)$ & $57(59,4 \%)$ & \multirow[t]{2}{*}{0,785} \\
\hline & Thành thị & $4(36,4 \%)$ & $39(40,6 \%)$ & \\
\hline \multicolumn{2}{|c|}{$\begin{array}{l}\text { Số bệnh đồng mằc } \\
\text { (Trung bình } \pm \text { Độ lệch chuẩn) }\end{array}$} & $2,36 \pm 0,92$ & $2,15 \pm 0,74$ & 0,395 \\
\hline
\end{tabular}

Không có mối liên quan có ý nghĩa thống kê giữa tuổi, giới, nơi sống, số bệnh đồng mắc và tình trạng chất lượng giấc ngủ kém.

Bảng 4. Mối liên quan giữa chất lượng giấc ngủ và các đặc điểm ĐTĐ

\begin{tabular}{|c|c|c|c|}
\hline Đặc điểm & $\begin{array}{c}\text { Chất lượng giấc ngủ } \\
\text { tốt }(\mathrm{n}=11)\end{array}$ & $\begin{array}{c}\text { Chất lượng giấc ngủ } \\
\text { kém }(\mathrm{n}=96)\end{array}$ & $\mathbf{p}$ \\
\hline Thời gian mắc ĐTĐ (năm) & $8,00 \pm 3,22$ & $9,81 \pm 5,14$ & 0,256 \\
\hline \begin{tabular}{l|l} 
Hạ đường huyết & Có \\
\end{tabular} & $1(9,1 \%)$ & $21(21,9 \%)$ & 0,454 \\
\hline
\end{tabular}




\begin{tabular}{|c|c|c|c|}
\hline Không & $10(90,9 \%)$ & $75(78,1 \%)$ & \\
\hline Số biến chứng trung bình & $1,00 \pm 0,89$ & $1,37 \pm 0,71$ & 0,111 \\
\hline
\end{tabular}

Không có mối liên quan có ý nghĩa thống kê giữa thời gian mắc ĐTĐ, hạ đường huyết và số biến chứng của $\mathrm{ÐTÐ} \mathrm{và} \mathrm{tình} \mathrm{trạng} \mathrm{chất} \mathrm{lượng} \mathrm{giấc} \mathrm{ngủ} \mathrm{kém.}$

\section{BÀN LUẬn}

Nghiên cứu của chúng tôi ghi nhận tuổi trung bình của các đối tượng nghiên cứu là $66,1 \pm 6,4$ (năm). Kết quả này thấp hơn trong nghiên cứu trước đây ở Trung Quốc, độ tuổi trung bình của người tham gia là $72,2 \pm 8,3$ (năm) [5]. Tỷ lệ bệnh nhân trong nhóm 60-69 tuổi chiếm $81,3 \%$, nhóm $\geq 70$ tuổi chiếm $18,7 \%$. Kết quả này trái ngược với nghiên cứu trên (ở Trung Quốc), tỷ lệ những người 60-69 tuổi chiếm $32,1 \%$ và $52,5 \%$ ở những người $\geq$ 80 tuổi [5]. Kết quả này có thể được giải thích bằng cỡ mẫu trong nghiên cứu này nhỏ hơn so với mẫu trong nghiên cứu trên (240 so với 1086 bệnh nhân) và đối tượng nghiên cứu tại bệnh viện Y học cổ truyền Hà Đông với đối tượng đến khám đa dạng. Tỉ lệ nữ giới trong nghiên cứu là $66,4 \%$ cao hơn so với nam giới là $33,6 \%$.

Trong nghiên cứu của chúng tôi ghi nhận tỉ lệ bệnh nhân có chất lượng giấc ngủ kém là $89,7 \%$ với điểm cắt của chỉ số chất lượng giấc ngủ chất lượng giấc ngủ Pittsburgh (Pittsburgh Sleep Quality Index - PSQI) là 8 điểm [6]. Tỷ lệ này cao hơn so với kết quả nghiên cứu của Bing-Qian Zhu và cộng sự (2014) với tỷ lệ chất lượng giấc ngủ kém là $47,1 \%$. Tổng điểm PSQI trung bình trong nghiên cứu của chúng tôi là $11,44 \pm 2,93$ cao hơn so với nghiên cứu của Bing-Qian Zhu là $8,3 \pm 4,12$ (điểm cắt $\mathrm{PSQI}$ là 8 điểm) [6] và cao hơn nghiên cứu của Luyster là $55 \%$ (điểm cắt PSQI là 5 điểm) [7]. Kết quả này có thể là do đối tượng nghiên cứu của chúng tôi là bệnh nhân ĐTĐ cao tuổi nên chất lượng giấc ngủ bị ảnh hưởng bởi nhiều yếu tố như tuổi cao, nhiều bệnh lý mắc kèm và các hội chứng lão khoa.

Nghiên cứu của chúng tôi ghi nhận trên 7 phương diện đánh giá rối loạn giấc ngủ (rối loạn giấc ngủ chủ quan, độ trễ giấc ngủ, thời gian ngủ, rối loạn giấc ngủ, dùng thuốc ngủ, hiệu quả giấc ngủ, rối loạn chức năng ban ngày), đa số các bệnh nhân có mức độ chất lượng/rối loạn giấc ngủ ở mức tương đối kém. Kết quả này cũng phù hợp với các nghiên cứu trước đây trên người cao tuổi trên thế giới.

Kết quả nghiên cứu của chúng tôi ghi nhận không có mối liên quan có ý nghĩa thống kê giữa tuổi trung bình, nhóm tuổi, giới, nơi sống, số bệnh đồng mắc và tỉ lệ chất lượng giấc ngủ kém ở đối tượng bệnh nhân ĐTĐ typ 2 cao tuổi điều trị tại bệnh viện Y học cổ truyền Hà Đông. Kết quả này khác với kết quả của nghiên cứu tại Trung Quốc rằng có mối liên quan giữa tỉ lệ chất lượng giấc ngủ kém và tuổi [5]. Kết quả này có thể do cỡ mẫu của chúng tôi còn nhỏ và là nghiên cứu cắt ngang.

Kết quả nghiên cứu của chúng tôi ghi nhận không có mối liên quan có ý nghĩa thống kê giữa thời gian mắc ĐTĐ trung bình, cơn hạ đường huyết và số biến chứng mạn tính trung bình của ĐTĐ và tỉ lệ chất lượng giấc ngủ kém ở đối tượng bệnh nhân ĐTĐ cao tuổi điều trị tại bệnh viện $\mathrm{Y}$ học cổ truyền Hà Đông. Kết quả này tượng tự với kết quả của nghiên cứu của Luyster và cộng sự (2011) rằng không có mối liên quan giữa tỉ lệ chất lượng giấc ngủ kém và thời gian mắc ĐTĐ có ý nghĩa thống kê $(p>0,05)$ [7]. Kết quả này có thể do cỡ mẫu của chúng tôi còn nhỏ và là nghiên cứu cắt ngang.

\section{KẾT LUẬN}

Tỷ lệ chất lượng giấc ngủ kém trên bệnh nhân ĐTĐ cao tuổi khám và điều trị tại bệnh viện Y học cổ truyền Hà Đông cao, do vậy cần sàng lọc và chẩn đoán sớm tình trạng rối loạn giấc ngủ trên người cao tuổi mắc ĐTĐ.

TÀI LIẸU THAM KHẢO

\section{International Diabetes Federation} (2015). IDF Diabetes Atlas 7th edition. 
71-73.

2. Gupta V, Suri P (2002). Diabetes in Elderly patients. JK Pract, 91(4), 258 259.

3. M. C. Volpato S, Fellin R (2010). Type 2 diabetes and risk for functional decline and disability in older persons. Curr Diabetes Rev; 6:134-143.

4. D. J. R. Buysse, Charles F.; Monk, Timothy H.; Berman, Susan R.; Kupfer, David J (1989). "The Pittsburgh sleep quality index: A new instrument for psychiatric practice and research". Psychiatry Research. 28 (2): 193-213.
5. J. Luo, et al. (2013) Prevalence and risk factors of poor sleep quality among Chinese elderly in an urban community: results from the Shanghai aging study. PloS one, 2013. 8(11): p. e81261

6. X.-M. Bing-QianZhu, DanWang, XingFengYu (2014). Sleep quality and its impact on glycaemic control in patients with type 2 diabetes mellitus. International Journal of Nursing Sciences, 1(3), 260-265

7. F. S. Luyster, J. Dunbar-Jacob (2011). Sleep quality and quality of life in adults with type 2 diabetes. Diabetes Educ, 37(3), 347-355. 